\title{
Association between psychiatric disorders and iron deficiency anemia among children and adolescents: a nationwide population-based study
}

\author{
Mu-Hong Chen ${ }^{1}$, Tung-Ping Su',2, Ying-Sheue Chen ${ }^{1}$, Ju-Wei Hsu' ${ }^{1}$ Kai-Lin Huang ${ }^{1}$, Wen-Han Chang ${ }^{1}$,
} Tzeng-Ji Chen ${ }^{3,4}$ and Ya-Mei Bai ${ }^{1,2^{*}}$

\begin{abstract}
Background: A great deal of evidence has shown that iron is an important component in cognitive, sensorimotor, and social-emotional development and functioning, because the development of central nervous system processes is highly dependent on iron-containing enzymes and proteins. Deficiency of iron in early life may increase the risk of psychiatric morbidity.

Methods: Utilizing the National Health Insurance Database from 1996 to 2008, children and adolescents with a diagnosis of IDA were identified and compared with age and gender-matched controls (1:4) in an investigation of the increased risk of psychiatric disorders.

Results: A total of 2957 patients with IDA, with an increased risk of unipolar depressive disorder $(\mathrm{OR}=2.34,95 \% \mathrm{Cl}=$ $1.58 \sim 3.46)$, bipolar disorder $(\mathrm{OR}=5.78,95 \% \mathrm{Cl}=2.23 \sim 15.05)$, anxiety disorder $(\mathrm{OR}=2.17,95 \% \mathrm{Cl}=1.49 \sim 3.16)$, autism spectrum disorder $(\mathrm{OR}=3.08,95 \% \mathrm{Cl}=1.79 \sim 5.28)$, attention deficit hyperactivity disorder $(\mathrm{OR}=1.67,95 \% \mathrm{Cl}=1.29 \sim 2.17)$, tic disorder $(\mathrm{OR}=1.70,95 \% \mathrm{Cl}=1.03 \sim 2.78)$, developmental delay $(\mathrm{OR}=2.45,95 \% \mathrm{Cl}=2.00 \sim 3.00)$, and mental retardation $(\mathrm{OR}=2.70,95 \% \mathrm{Cl}=2.00 \sim 3.65)$, were identified. A gender effect was noted, in that only female patients with IDA had an increased $\mathrm{OR}$ of bipolar disorder $(\mathrm{OR}=5.56,95 \% \mathrm{Cl}=1.98 \sim 15.70)$ and tic disorder ( $\mathrm{OR}=2.95,95 \% \mathrm{Cl}=1.27 \sim 6.86)$.
\end{abstract}

Conclusion: Iron deficiency increased the risk of psychiatric disorders, including mood disorders, autism spectrum disorder, attention deficit hyperactivity disorder, and developmental disorders. Further study is required to clarify the mechanism in the association between IDA and psychiatric disorder.

Keywords: Iron deficiency anemia, Psychiatric disorders, Comorbidity

\section{Background}

According to the World Health Organization, iron deficiency (ID) is the most prevalent nutritional deficiency. A $30 \%$ prevalence of iron deficiency anemia (IDA), at a minimum, has been noted among children, adolescents, and women in non-industrialized countries, and ID is also the most prevalent nutritional deficiency in industrialized countries [1-4]. ID, defined by two or more abnormal measurements (serum ferritin, transferrin saturation,

\footnotetext{
* Correspondence: ymbi@mail2000.com.tw

'Department of Psychiatry, Taipei Veterans General Hospital, Taipei, Taiwan

${ }^{2}$ Department of Psychiatry, College of Medicine, National Yang-Ming

University, Taipei, Taiwan

Full list of author information is available at the end of the article
}

erythrocyte protoporphyrin), is insidious and uneasily detected by patients themselves and may not develop significant clinical symptoms [1-4]. IDA is characterized by a defect in hemoglobin synthesis owing to significant ID, resulting in the reduced capacity of the red blood cells to deliver oxygen to body cells and tissues, and many clinical symptoms, such as pale conjunctiva, shortness of breath, dizziness, and lethargy [1-4]. The main risk factors for IDA and ID include a low intake of iron, poor absorption of iron from diets, chronic loss of iron (i.e., ulcer, metrorrhagia), and some specific periods of life when iron requirements are especially high, such as growth and pregnancy [1-4].

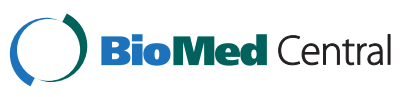


Iron is an essential component of hemoglobin, myoglobin, and many enzymes in cellular metabolism and DNA replication and repair. It also plays a crucial role in the development of the central neurological system [5-8], autoimmune system [9-11], endocrine system [12-15], and cardiovascular system [16,17]. In the development of the brain, iron accounted for the myelination of white matter $[18,19]$ and the development and functioning of the different neurotransmitter systems, including the dopamine, norepinephrine, and serotonin systems [20-22]. In vivo microdialysis studies using postweaning iron-deficient rats and mice demonstrated that they exhibited deficits in intracellular dopamine concentrations and in the density of dopamine and dopamine transporter receptors, with variable amounts of loss by brain region [23-26]. Anderson et al. showed that decreased iron significantly reduced extracellular concentrations of norepinephrine in the caudate putamen, and altered levels of norepinephrine due to reduced iron levels may be the result of changes in the expression of norepinephrine transport and norepinephrine receptor proteins in the locus ceruleus and basal ganglia [27,28]. A reduction in serotonin transporter binding was noted in the nucleus accumbens and olfactory tubercle in irondeficient rats [21], and the serotonin concentration in the brain was significantly correlated with the non-heme iron level [29].

In summary, IDA and ID were significantly associated with an alteration of monoamine neurotransmitters and the abnormal myelination of white matter, and is probably related to childhood/adolescence-onset psychiatric disorders. There is well documented evidence in the literature that IDA has a significant influence on cognitive development, intelligence, and developmental delay $[30,31]$. However, the association between IDA and other childhood/adolescence-onset psychiatric disorders is still limited. Some clinical studies supposed that brain ID involved in the pathophysiology of attention deficit hyperactivity disorder (ADHD) [32] and ferritin level was related to behavioral symptoms in ADHD patients [33]. But, Millichap et al. disclosed no significant difference in severity of ADHD symptoms between children with ADHD who had the lower serum ferritin levels $(<20 \mathrm{ng} /$ $\mathrm{mL})$ and those who had the higher levels $(>60 \mathrm{ng} / \mathrm{mL})$ [34]. And a high prevalence, up to $30 \%$, of IDA was observed in children with autism spectrum disorder (ASD), which was supposed to potentially compromise their communication and behavior [35,36]. As for schizophrenia, bipolar disorder (BD), unipolar depressive disorder, and anxiety disorder, the data are quite limited. This study, using a nationwide population-based insurance database with a case-control method and the largest sample size, attempted to clarify the association between IDA and various psychiatric disorders among children and adolescents with IDA. We hypothesized that children and adolescents with ADHD exhibited the higher risk of having a psychiatric disorder.

\section{Methods}

\section{Data source}

The National Health Insurance (NHI) program was implemented in Taiwan in 1995. Since 2001, Taiwan's NHI has covered $96.9 \%$ of all $23,000,000$ residents of Taiwan. The completeness and accuracy of the NHI claims database has been audited by the Department of Health and the Bureau of NHI. The database provides demographic and medical information on insured residents, including age, gender, prescription drugs, prescription date, and the prescription and diagnosis using the International Classification of Diseases, 9th Revision, Clinical Modification (ICD-9-CM). The NHI Research Database (NHIRD) has been used extensively in many epidemiologic studies in Taiwan [37-39]. Our study was approved by Institutional Review Board of Taipei Veterans General Hospital (2012-04-012BC).

\section{Inclusion criteria for IDA and psychiatric disorders}

In this study, 1,000,000 subjects, approximately $4.3 \%$ of the population of Taiwan, were randomly selected from the NHIRD. The study comprised all children and adolescents (aged younger than 18) who were identified by the diagnostic code of "iron deficiency anemia" (ICD-9-CM: 280) between January 1, 1996 and December 31, 2008. Diagnosis was given by board-certificated pediatricians and physicians. Coexistent psychiatric disorders were investigated by specific diagnostic codes, and included schizophrenia (ICD9-CM code: 295), BD (ICD-9-CM code: 296 except 296.2 and 296.3), unipolar depressive disorder (ICD-9-CM codes: 296.2, 296.3, 300.4, and 311 for major depressive disorder, dysthymic disorder, depressive disorder, not specified), obsessive-compulsive disorder (OCD) (ICD-9-CM code: 300.3), anxiety disorder (ICD-9-CM code: 300 except 300.3 and 300.4), ASD (ICD-9-CM code: 299), ADHD (ICD-9CM code: 314), tic disorder (ICD-9-CM: 307.2), delayed development (ICD-9-CM code: 315), and mental retardation (ICD-9-CM code: $317 \sim 319$ ). Finally, gastrointestinal ulcer (ICD-9-CM code: $531 \sim 534$ ), metrorrhagia (ICD-9-CM code: 626.2 and 626.6), and premenopausal menorrhea (ICD-9-CM code: 627.0) were used as covariates. All psychiatric diagnoses were given by board-certified psychiatrists. The diagnoses of delayed development and mental retardation were given by board-certificated psychiatrists, rehabilitation specialists, and pediatricians.

\section{Control group}

The age and gender-matched control group (4 for every patient in the study cohort) was randomly identified from subjects who had no major physical illnesses, 
including cancer (ICD-9-CM code: $140 \sim 239$ ), hematological disease (ICD-9-CM code: $280 \sim 289$ ), chronic liver disease (ICD-9-CM code: $570 \sim 573$ ), chronic renal disease (ICD-9-CM code: 585,586 ), chronic inflammatory disease (ICD-9-CM code: 710 for diffuse diseases of connective tissue, 714 for rheumatoid arthritis and other inflammatory polyarthropathies, 720 for ankylosing spondylitis and other inflammatory spondylopathies, 555 for Crohn's disease, 556 for idiopathic proctocolitis), chronic infectious disease (ICD-9-CM code: 010 018 for tuberculosis, $042 \sim 044$ for human immunodeficiency virus, 070 for viral hepatitis, $090 \sim 099$ for syphilis, $390 \sim 392$ for rheumatic fever, 730 for osteomyelitis), endocrine disease (ICD-9-CM code: $240 \sim 246$ for thyroid disease, $249 \sim 250$ for diabetes mellitus, 252 for parathyroid disease, 253 for pituitary disease, 255 for adrenal gland disease), and nutritional deficiency (ICD-9-CM code: $260 \sim 269$ ).

\section{Statistical analysis}

For between-group comparisons, the independent $t$ test was used for continuous variables and Pearson's $X^{2}$ test or Fisher's exact test was applied for nominal variables, where appropriate. Multiple logistic regressions were performed to calculate the OR with $95 \%$ confidence intervals (CI) after adjusting for ulcer, metrorrhagia, and premenopausal menorrhea (because ulcer and metrorrhagia were two important risks causing IDA of children and adolescents). A two-tailed $P$-value of less than 0.05 was considered statistically significant. All data processing and statistical analyses were performed with Statistical Package for Social Science (SPSS) version 17 software (SPSS Inc) and Statistical Analysis Software (SAS) version 9.1 (SAS Institute, Cary, NC).

\section{Results}

Demographic characteristics of the IDA patients and control group

A total of 2957 children and adolescents (1060 males and 1897 females) were identified as having IDA from the 1,000,000-person sample population between January 1, 1996 and December 31, 2008. The mean age was $10.59 \pm 6.02$ years and male patients were significantly younger than the females $(7.46 \pm 5.68$ vs. $12.34 \pm 5.46$, $\mathrm{p}<0.001$ ). Male IDA patients exhibited a significantly higher prevalence of ASD $(1.6 \%$ vs. $0.4 \%, \mathrm{p}<0.001)$, ADHD $(6.0 \%$ vs. $1.1 \%, \mathrm{p}<0.001)$, tic disorder $(1.3 \%$ vs. $0.5 \%, \mathrm{p}=0.027)$, delayed development $(8.5 \%$ vs. $3.4 \%$, $\mathrm{p}<0.001)$, and mental retardation $(4.4 \%$ vs. $1.5 \%, \mathrm{p}<$ 0.001 ) than the females (Table 1). In comparing the difference between the IDA patients and the control group, the IDA patients had a significantly increased prevalence of psychiatric comorbidities, including unipolar depressive disorder $(1.6 \%$ vs. $0.6 \%, \mathrm{p}<0.001)$, BD $(0.4 \%$ vs. $0.1 \%, \mathrm{p}<0.001)$, anxiety disorder $(1.5 \%$ vs. $0.7 \%, \mathrm{p}<$ $0.001)$, $\operatorname{ASD}(0.8 \%$ vs. $0.3 \%, \mathrm{p}<0.001), \operatorname{ADHD}(2.8 \%$ vs. $1.8 \%, \mathrm{p}<0.001)$, tic disorder $(0.8 \%$ vs. $0.5 \%, \mathrm{p}=0.044)$, delayed development $(5.2 \%$ vs. $2.4 \%, \mathrm{p}<0.001)$, and mental retardation $(2.5 \%$ vs. $1.0 \%, \mathrm{p}<0.001)$ (Table 2$)$.

\section{Odds ratio of psychiatric disorders}

In examining the association between IDA and childhood/adolescence-onset psychiatric disorders, multiple logistic regression analysis was used to evaluate the OR of psychiatric comorbidity among those with IDA, after adjusting for age, gender, ulcer, metrorrhagia, and premenopausal menorrhea. Patients with IDA were prone to having a significantly higher chance of being associated with unipolar depressive disorder $(\mathrm{OR}=2.34$,

Table 1 Characteristics of patients with iron deficiency anemia (IDA)

\begin{tabular}{|c|c|c|c|c|}
\hline Characteristics of IDA & Male & Female & $p$-value & All \\
\hline No. & 1060 & 1897 & & \\
\hline Age (years) & $7.46 \pm 5.68$ & $12.34 \pm 5.46$ & $<0.001$ & $10.59 \pm 6.02$ \\
\hline \multicolumn{5}{|l|}{ Associated diseases, N (\%) } \\
\hline Schizophrenia & $2(0.2)$ & $6(0.3)$ & 0.719 & $8(0.3)$ \\
\hline Unipolar depressive disorder & $12(1.1)$ & $36(1.9)$ & 0.104 & $48(1.6)$ \\
\hline Bipolar disorder & $2(0.2)$ & $11(0.6)$ & 0.154 & $13(0.4)$ \\
\hline OCD & $1(0.1)$ & $3(0.2)$ & $>0.999$ & $4(0.1)$ \\
\hline Anxiety disorder & $21(2.0)$ & $24(1.3)$ & 0.158 & $45(1.5)$ \\
\hline ASD & $17(1.6)$ & $7(0.4)$ & 0.001 & $24(0.8)$ \\
\hline ADHD & $64(6.0)$ & $20(1.1)$ & $<0.001$ & $84(2.8)$ \\
\hline Tic disorder & $14(1.3)$ & $9(0.5)$ & 0.027 & $23(0.8)$ \\
\hline Delayed development & $90(8.5)$ & $64(3.4)$ & $<0.001$ & $154(5.2)$ \\
\hline Mental retardation & $47(4.4)$ & $28(1.5)$ & $<0.001$ & $75(2.5)$ \\
\hline
\end{tabular}

$O C D$ obsessive-compulsive disorder, $A S D$ autistic spectrum disorder, $A D H D$ attention-deficit hyperactivity disorder. 
Table 2 Characteristics of patients with iron deficiency anemia (IDA) and control subjects

\begin{tabular}{lccc}
\hline Characteristics & IDA & Control & $\boldsymbol{p}$-value \\
\hline No. & 2957 & 11828 & \\
Age (years) & $10.59 \pm 6.02$ & $10.59 \pm 6.02$ & \\
Sex, N (\%) & & & \\
Male & $1060(35.8)$ & $4240(35.8)$ & \\
Female & $1897(64.2)$ & $7588(64.2)$ & \\
Associated diseases, N (\%) & & & \\
Schizophrenia & $8(0.3)$ & $14(0.1)$ & 0.063 \\
Unipolar depressive disorder & $48(1.6)$ & $66(0.6)$ & $<0.001$ \\
Bipolar disorder & $13(0.4)$ & $7(0.1)$ & $<0.001$ \\
OCD & $4(0.1)$ & $8(0.1)$ & 0.274 \\
Anxiety disorder & $45(1.5)$ & $80(0.7)$ & $<0.001$ \\
ASD & $24(0.8)$ & $32(0.3)$ & $<0.001$ \\
ADHD & $84(2.8)$ & $207(1.8)$ & $<0.001$ \\
Tic disorder & $23(0.8)$ & $56(0.5)$ & 0.044 \\
Delayed development & $154(5.2)$ & $278(2.4)$ & $<0.001$ \\
Mental retardation & $75(2.5)$ & $114(1.0)$ & $<0.001$ \\
\hline DA iron deficiency and & & & \\
\end{tabular}

IDA iron deficiency anemia, OCD obsessive-compulsive disorder, $A S D$ autistic spectrum disorder, $A D H D$ attention-deficit and hyperactivity disorder.

$95 \% \mathrm{CI}=1.59 \sim 3.46), \mathrm{BD}(\mathrm{OR}=5.80,95 \% \mathrm{CI}=2.24 \sim$ 15.05), anxiety disorder $(\mathrm{OR}=2.17,95 \% \mathrm{CI}=1.49 \sim$ 3.16), $\mathrm{ASD}(\mathrm{OR}=3.08,95 \% \mathrm{CI}=1.79 \sim 5.28)$, ADHD $(\mathrm{OR}=1.67,95 \% \mathrm{CI}=1.29 \sim 2.17)$, tic disorder $(\mathrm{OR}=$ 1.70, $95 \% \mathrm{CI}=1.03 \sim 2.78$ ), delayed development $(\mathrm{OR}=$ $2.45,95 \% \mathrm{CI}=2.00 \sim 3.00)$, and mental retardation $(\mathrm{OR}=2.70,95 \% \mathrm{CI}=2.00 \sim 3.65)$ (Table 3$)$. We also investigated the gender effect on IDA and associated psychiatric comorbidities (Table 3). A significantly increased risk of unipolar depressive disorder $(\mathrm{OR}=2.36,95 \%$ $\mathrm{CI}=1.10 \sim 5.10)$, anxiety disorder $(\mathrm{OR}=1.73,95 \% \mathrm{CI}=$ $1.02 \sim 2.94), \quad$ ASD $\quad(\mathrm{OR}=2.66,95 \% \quad \mathrm{CI}=1.41 \sim 5.00)$, ADHD $\quad(\mathrm{OR}=1.51, \quad 95 \% \quad \mathrm{CI}=1.12 \sim 2.04), \quad$ delayed development $\quad(\mathrm{OR}=1.95, \quad 95 \% \quad \mathrm{CI}=1.50 \sim 2.53)$, and mental retardation $(\mathrm{OR}=3.09,95 \% \quad \mathrm{CI}=2.08 \sim 4.61)$ were observed in male IDA patients in comparison with females, while a significantly higher risk of unipolar depressive disorder $(\mathrm{OR}=2.37,95 \% \mathrm{CI}=1.51 \sim 3.73), \mathrm{BD}$ $(\mathrm{OR}=5.56, \quad 95 \% \quad \mathrm{CI}=1.98 \sim 15.70), \quad$ anxiety disorder $(\mathrm{OR}=2.69,95 \% \mathrm{CI}=1.57 \sim 4.62), \mathrm{ASD}(\mathrm{OR}=4.07,95 \%$ $\mathrm{CI}=1.39 \sim 11.90), \quad \mathrm{ADHD} \quad(\mathrm{OR}=2.00,95 \% \mathrm{CI}=1.14 \sim$ $3.49)$, tic disorder $(\mathrm{OR}=2.95,95 \% \mathrm{CI}=1.27 \sim 6.86)$, delayed development $(\mathrm{OR}=3.48,95 \% \mathrm{CI}=2.48 \sim 4.88)$, and mental retardation $(\mathrm{OR}=2.13,95 \% \mathrm{CI}=1.34 \sim 3.40)$ were noted in female IDA patients compared with males (Table 3).

\section{Odds ratio of psychiatric disorder stratified by age}

We performed adjusted multiple logistic regression stratified by age to elucidate the association between IDA and various psychiatric comorbidities, focusing on children and adolescents with IDA, respectively (Table 3 ). Children were defined as those younger than 13 and adolescents as those aged $13 \sim 18$. Children with IDA exhibited a significantly higher risk of $\mathrm{ASD}(\mathrm{OR}=3.00,95 \% \mathrm{CI}=1.70 \sim$ 5.27), $\mathrm{ADHD}(\mathrm{OR}=1.50,95 \% \mathrm{CI}=1.12 \sim 1.99)$, delayed development $(\mathrm{OR}=2.23,95 \% \mathrm{CI}=1.79 \sim 2.78)$, and mental retardation $(\mathrm{OR}=3.01,95 \% \mathrm{CI}=2.09 \sim 4.32)$ (Table 3$)$. Adolescents with IDA were significantly associated with unipolar depressive disorder $(\mathrm{OR}=2.89,95 \% \mathrm{CI}=1.84$ 4.54), $\mathrm{BD}(\mathrm{OR}=6.05,95 \% \mathrm{CI}=1.97 \sim 18.58)$, anxiety disorder $(\mathrm{OR}=3.71,95 \% \mathrm{CI}=2.16 \sim 6.37)$, ADHD $(\mathrm{OR}=$ $2.54,95 \% \mathrm{CI}=1.31 \sim 4.95)$, tic disorder $(\mathrm{OR}=3.73,95 \%$ $\mathrm{CI}=1.12 \sim 12.48)$, delayed development $(\mathrm{OR}=3.88,95 \%$ $\mathrm{CI}=2.17 \sim 6.95)$, and mental retardation $(\mathrm{OR}=2.08,95 \%$ $\mathrm{CI}=1.22 \sim 3.57$ ) (Table 3 ).

\section{Discussion}

The results of our clinical epidemiological study supported previous findings that IDA is significantly

Table 3 Association between iron deficiency anemia (IDA) and psychiatric disorders

\begin{tabular}{|c|c|c|c|c|c|}
\hline OR $(95 \% \mathrm{Cl})$ & Male & Female & Children (Age <13) & Adolescent (Age $\geqq 13$ ) & All \\
\hline Schizophrenia & $2.20(0.40,12.02)$ & $2.15(0.76,6.10)$ & $4.35(0.27,69.56)$ & $2.04(0.79,5.28)$ & $2.11(0.86,5.15)$ \\
\hline Unipolar depressive disorder & $2.36(1.10,5.10)$ & $2.37(1.51,3.73)$ & $1.33(0.58,3.04)$ & $2.89(1.84,4.54)$ & $2.34(1.59,3.46)$ \\
\hline Bipolar disorder & $8.80(0.80,97.14)$ & $5.56(1.98,15.70)$ & $5.20(0.83,32.71)$ & $6.05(1.97,18.58)$ & $5.80(2.24,15.05)$ \\
\hline OCD & $0.78(0.08,7.48)$ & $3.07(0.67,14.13)$ & - & $3.01(0.77,11.77)$ & $1.87(0.55,6.40)$ \\
\hline Anxiety disorder & $1.73(1.02,2.94)$ & $2.69(1.57,4.62)$ & $1.29(0.74,2.26)$ & $3.71(2.16,6.37)$ & $2.17(1.49,3.16)$ \\
\hline ASD & $2.66(1.41,5.00)$ & $4.07(1.39,11.90)$ & $3.00(1.70,5.27)$ & $2.55(0.40,16.24)$ & $3.08(1.79,5.28)$ \\
\hline ADHD & $1.51(1.12,2.04)$ & $2.00(1.14,3.49)$ & $1.50(1.12,1.99)$ & $2.54(1.31,4.95)$ & $1.67(1.29,2.17)$ \\
\hline Tic disorder & $1.23(0.66,2.30)$ & $2.95(1.27,6.86)$ & $1.41(0.81,2.43)$ & $3.73(1.12,12.48)$ & $1.70(1.03,2.78)$ \\
\hline Delay in development & $1.95(1.50,2.53)$ & $3.48(2.48,4.88)$ & $2.23(1.79,2.78)$ & $3.88(2.17,6.95)$ & $2.45(2.00,3.00)$ \\
\hline Mental retardation & $3.09(2.08,4.61)$ & $2.13(1.34,3.40)$ & $3.01(2.09,4.32)$ & $2.08(1.22,3.57)$ & $2.70(2.00,3.65)$ \\
\hline
\end{tabular}

$O C D$ obsessive-compulsive disorder, $A S D$ autistic spectrum disorder, $A D H D$ attention-deficit hyperactivity disorder. Bold type denotes statistically significant odds ratio (OR). 
associated with increased risks of unipolar depressive disorder, BD, anxiety disorder, ASD, ADHD, delayed development, and mental retardation among children and adolescents.

\section{Mental retardation and delayed development}

Our results showed a higher prevalence of mental retardation and delayed development among subjects with IDA, which was consistent with previous findings $[31,40,41]$. Beltrán-Navarro et al. used the Bayley Scales of Infant Development, preschool language scales and an environmental sound perception task to assess the effect of IDA on multifaceted development in infancy (at 6 and 14 to 18 months) and showed that infants with chronic IDA did show significantly lower scores on language, environmental sound perception, and motor measures, when compared with infants with a normal iron nutritional status [42]. Studying the long-term developmental outcome of infants with IDA, Lozoff et al. found lower scores on tests of mental (i.e., intelligence) and motor functioning at age of 5 and 12 among those with IDA in infancy $[31,40]$. Furthermore, IDA can impair cognitive performance at all stages of life. Halterman et al. assessed 5398 children and adolescents aged 6 to 16 and demonstrated that subjects with IDA had more than twice the risk of scoring below average in scholastic achievement than the children with a normal iron status [43].

\section{Attention deficit hyperactivity disorder (ADHD)}

Previous studies on iron and the pathophysiology of ADHD have had inconsistent results. In a small cohort study comprising 52 ADHD children, Oner et al. found that lower ferritin levels were associated with higher hyperactivity scores in ADHD children, but did not have a significant influence on cognitive measures [33]. Using magnetic resonance imaging (MRI) to investigate the association of ADHD and brain iron levels in the putamen, pallidum, caudate, and thalamus, Cortese et al. demonstrated children with ADHD showed significantly lower brain iron levels in the right and left thalamus compared to healthy controls [32]. Other studies, however, did not find this association between ADHD and the ferritin level $[34,44]$. In our study, an increased risk of ADHD was noted among those with IDA, which was compatible with a recent meta-analysis result [45]. With regard to the current pathophysiology of ADHD as involving a dysfunction of the neurotransmitter systems, IDA significantly disturbed the development and functioning of norepinephrine and dopamine neurotransmitter systems.

\section{Autism spectrum disorder (ASD)}

Previous studies have revealed that iron was associated with socio-cognitive and socio-emotional development and functioning [46-48]. A disorder in this area is one of the core symptoms of ASD. Assessing the prevalence of ID and IDA among 116 children between 3 and 16 years old with a diagnosis of ASD, Hergüner et al. revealed that $24 \%$ of patients with ASD had ID, and 15\% had IDA [35]. Latif et al. analyzed the serum ferritin measurements of 96 children with ASD and suggested there was a high prevalence, up to 30 percent, of ID in children with ASD [36]. Our result showed an increased risk of ASD among children and adolescents with IDA, suggesting a possible reciprocal effect between ASD and IDA. For example, inappropriate eating habit in those subjects may be related to IDA and many children with ASD are picky eaters, which could contribute to IDA. Furthermore, diffusion-tensor MRI found impaired white matter integrity and a myelination developmental abnormality in ASD patients compared to normal subjects [49-51]. Iron was regarded as an essential component in myelination and oligodendrogenesis. Myelin synthesis was limited and altered by ID. Further study would be needed to clarify the comorbidity or causality between ASD and IDA.

\section{Unipolar depressive disorder}

Numerous studies have reported that IDA was associated with unipolar depressive disorder, possibly through an alteration of the monoamine neurotransmitters by ID [52-54]. Lower serum ferritin concentrations were significantly correlated with depressive symptoms [53,54]. Using a longitudinal cohort study of 191 participants to evaluate the association between IDA in infancy and affective and developmental outcomes in adolescence, Lozoff et al. revealed that those with IDA in infancy exhibited more anxiety, depression, social problems, and attentional problems in later life [40]. Vahdat Shariatpanaahi et al. studied 192 female medical students and found the mean ferritin level of students with depression was significantly lower than that of healthy students [53]. Similar results were observed in a Japanese male population. In a study of 312 men, those with lower serum ferritin concentration levels had a higher prevalence of depressive symptoms [54]. Our result, showing an increased risk of unipolar depressive disorder among those with IDA, was compatible with that of previous studies, and reconfirmed the pathophysiological association of IDA with unipolar depressive disorder.

\section{Bipolar disorder (BD)}

Emotional dysregulation has been deemed as one of the core neuropsychopathologies of BD [55-57]. It has been well documented that iron is associated with socioemotional development and that ID may disturb the development of emotional regulation [40,46,47,58], although clinical studies on the association between IDA and $\mathrm{BD}$ are few. Our results showed a higher prevalence of BD among IDA subjects. Structural and functional 
changes related to emotional dysregulation such as in the dorsal and ventral prefrontal cortices and the prefrontal-subcortical and associated limbic circuitry have been considered as a neuropathology of BD $[56,57]$. ID has been related to perturbations in myelin formation, alterations of monoamine neurotransmitter systems, particularly in the striatum, and deficits in energy metabolism, particularly in the hippocampus and prefrontal cortex $[59,60]$. The effect of IDA on BD is still unclear and further study is needed to investigate the possible causality between IDA and BD. Furthermore, a significantly increased OR of BD was noted only among females with IDA after controlling gastrointestinal ulcer, metrorrhagia, and premenopausal menorrhea. Clarifying this gender effect between IDA and BD may be needed in future studies.

\section{Anxiety disorder}

Clinical studies on the association between IDA and anxiety disorder are few. Lozoff et al. found that children with severe, chronic ID in infancy had a greater prevalence of anxiety, depression, and attention problems [40]. Some animal studies have shown an association between IDA and alterations in serotonin, norepinephrine, and gamma-aminobutyric acid (GABA) neurotransmission $[21,61]$. In assessing weanling rats with either an iron deficient diet or a control diet for 6 weeks, Beard et al. found reduced activity and increased anxiety-like behaviors among the iron deficient rats with significant decrements in brain iron content in the corpus striatum, prefrontal cortex, and midbrain [62]. Emotional dysregulation due to ID may be a possible mechanism explaining the association between anxiety and IDA [63-65]. In our study, both males and females with IDA had a significantly higher risk of anxiety disorder. However, establishing causality between IDA and anxiety disorder will require further study in the future.

Regarding emotional and cognitive problems, current neuroanatomical imaging studies have proven that brain development is a continuous process from infancy to late adolescence or early adulthood [66,67]. A deficiency of essential components will greatly impair the normal trajectory of brain development. Iron is regarded as one of the essential nutritional elements related to cognitive and socio-emotional development and functioning. A significantly higher risk of anxiety disorder, ASD, ADHD, delayed development, and mental retardation was noted among children (below age 13) with IDA. After entering adolescence (age 13 18), those with IDA had an increased risk of unipolar depressive disorder, BD, anxiety disorder, ADHD, delayed development, and mental retardation. These results may indicate that ID, whether in childhood or adolescence, does have a great impact on psychiatric comorbidities. Moreover, iron deletion in childhood has immediate and chronic effects on brain development, in that children with IDA exhibited an increased risk of delayed development and mental retardation with persistent sequelae of cognitive impairment and emotional problems during adolescence.

\section{Tic disorder}

We found a significantly increased risk of tic disorder among females with IDA. The association between IDA and tic disorder is unclear and rarely reported in the literature. Cortese et al. mentioned a possible iron hypothesis in a possible spectrum disorder of ADHD, restless leg syndrome, and tic disorder, because these 3 disorders were sometimes comorbid and shared a pathogenesis similar to monoamine neurotransmitter dysfunction [68]. Exploring the associations of ferritin levels with regional brain volumes among patients with Tourette's syndrome, Gorman et al. demonstrated ferritin and serum iron levels were significantly lower in the Tourette's syndrome subjects and that ferritin correlated positively with putamen volume [69]. Combining these results with ours may inspire further study to clarify the effect of iron on tic disorder or other movement disorders, especially in female populations.

Some limitations in our study should be mentioned here. First, the prevalence of psychiatric disorders was deemed underestimated because our results were derived from insurance registry-based data. Only those individuals who used the medical resource to seek psychiatric help were identified. However, patients included in our study were given a diagnosis by boardcertified physicians and the diagnoses were more reliable than self-reported ones. Second, those subjects who were not diagnosed as having IDA ever but had iron deficiency problem cannot be detected in our study. The clinical study would be required to elucidate the possible association between psychiatric disorders and iron deficiency or subthreshold IDA. Third, ID may be due to inappropriate eating habits in some cases but the association among IDA, eating disorder, and episodic mood disorder with changed eating pattern is still unclear. In our study, we focused on the risks of psychiatric comorbidities in patients with IDA and the further study is required to analyze the effect of inappropriate eating pattern of specific psychiatric disorder on the risk of IDA. Fourth, we had no personal information that could contribute to an understanding of the risk of psychiatric disorders in patients, such as environmental factors (i.e. long-term life stress, traumatic experience), and family history of psychiatric disorder. Forth, the causality between IDA and psychiatric disorders cannot be proved in our study, even though our results did indicate a significant association between IDA and psychiatric disorders. 


\section{Conclusions}

In conclusion, patients with IDA did have a higher risk of psychiatric disorders, including unipolar depressive disorder, BD, anxiety disorder, ASD, ADHD, delayed development, and mental retardation. When encountering patients with IDA in clinical practice, prompt iron supplementation should be considered to prevent possible psychiatric sequelae, because ID does impair the development of emotional regulation and cognition. And vice versa, psychiatrists should check the iron level in those children and adolescents with psychiatric disorders. Finally, further well-designed cohort studies are needed to elucidate the causality or comorbid effect between IDA and psychiatric disorders.

\section{Competing interests}

The authors declare that they have no competing interest.

\section{Authors' contributions}

$M H C$ and $Y M B$ designed the study, wrote the protocol and manuscripts. YMB, TPS, YSC, JWH, and KLH contributed to the preparation and proofreading of the manuscript. $Y M B, T J C$, and $W H C$ provided the advices on statistical analysis. All authors read and approved the final manuscript.

\section{Acknowledgement}

The study was supported by grant from Taipei Veterans General Hospital (V101D-001-1)

\section{Author details}

${ }^{1}$ Department of Psychiatry, Taipei Veterans General Hospital, Taipei, Taiwan. ${ }^{2}$ Department of Psychiatry, College of Medicine, National Yang-Ming University, Taipei, Taiwan. ${ }^{3}$ Department of Family Medicine, Taipei Veterans General Hospital, Taipei, Taiwan. ${ }^{4}$ Institute of Hospital and Health Care Administration, National Yang-Ming University, Taipei, Taiwan.

Received: 11 May 2012 Accepted: 28 May 2013

Published: 4 June 2013

\section{References}

1. DeMaeyer $E$, Adiels-Tegman M: The prevalence of anaemia in the world. World Health Stat Q 1985, 38(3):302-316.

2. Joint World Health Organization/Centers for Disease Control and Prevention Technical Consultation on the Assessment of Iron Status at the Population Level (2004: Geneva Switzerland), World Health Organization, Dept. of Nutrition for Health and Development: Assessing the iron status of populations: report of a joint world health organization/centers for disease control and prevention technical consultation on the assessment of iron status at the population level. Geneva, Switzerland: Geneva: World Health Organization; 2005.

3. World Health Organization: Worldwide prevalence of anaemia 1993-2005: WHO global database on anaemia. Geneva: World Health Organization; 2008.

4. World Health Organization, Dept. of Nutrition for Health and Development: Iron deficiency anaemia: assessment, prevention and control: a guide for programme managers. Geneva: World Health Organization; 2001

5. Pollitt E: Effects of a diet deficient in iron on the growth and development of preschool and school-age children. Food Nutr Bull 1991, 13:110-118.

6. Krebs NF: Dietary zinc and iron sources, physical growth and cognitive development of breastfed infants. J Nutr 2000, 130(2S Suppl):358S-360S.

7. Lind T, Lonnerdal B, Stenlund H, Gamayanti IL, Ismail D, Seswandhana R, Persson LA: A community-based randomized controlled trial of iron and zinc supplementation in Indonesian infants: effects on growth and development. Am J Clin Nutr 2004, 80(3):729-736.

8. Webb TE, Oski FA: Iron deficiency anemia and scholastic achievement in young adolescents. J Pediatr 1973, 82(5):827-830.
9. Gershwin ME, Keen CL, Mareschi JP, Fletcher MP: Trace metal nutrition and the immune response. Compr Ther 1991, 17(3):27-34.

10. Joynson DH, Walker DM, Jacobs A, Dolby AE: Defect of cell-mediated immunity in patients with iron-deficiency anaemia. Lancet 1972 2(7786):1058-1059

11. Srikantia SG, Prasad JS, Bhaskaram C, Krishnamachari KA: Anaemia and immune response. Lancet 1976, 1(7973):1307-1309.

12. Beard $\lrcorner \mathrm{L}$, Borel MJ, Derr J: Impaired thermoregulation and thyroid function in iron-deficiency anemia. Am J Clin Nutr 1990, 52(5):813-819.

13. Eftekhari MH, Eshraghian MR, Mozaffari-Khosravi $H$, Saadat N, Shidfar F: Effect of iron repletion and correction of iron deficiency on thyroid function in iron-deficient Iranian adolescent girls. Pak J Biol Sci 2007, 10(2):255-260.

14. Isguven P, Arslanoglu I, Erol M, Yildiz M, Adal E, Erguven M: Serum levels of ghrelin, leptin, IGF-I, IGFBP-3, insulin, thyroid hormones and cortisol in prepubertal children with iron deficiency. Endocr J 2007, 54(6):985-990.

15. Zimmermann MB: The influence of iron status on iodine utilization and thyroid function. Annu Rev Nutr 2006, 26:367-389.

16. Andersen HS, Gambling L, Holtrop G, McArdle HJ: Maternal iron deficiency identifies critical windows for growth and cardiovascular development in the rat postimplantation embryo. J Nutr 2006, 136(5):1171-1177.

17. Toxqui L, De Piero A, Courtois V, Bastida S, Sanchez-Muniz FJ, Vaquero MP: Iron deficiency and overload. Implications in oxidative stress and cardiovascular health. Nutr Hosp 2010, 25(3):350-365.

18. Beard JL: Why iron deficiency is important in infant development. J Nutr 2008, 138(12):2534-2536.

19. Beard $J \mathrm{~L}$, Wiesinger JA, Connor JR: Pre- and postweaning iron deficiency alters myelination in Sprague-Dawley rats. Dev Neurosci 2003, 25(5):308-315.

20. Beard J: Iron deficiency alters brain development and functioning. J Nutr 2003, 133(5 Suppl 1):1468S-1472S.

21. Burhans MS, Dailey C, Beard Z, Wiesinger J, Murray-Kolb L, Jones BC, Beard $\mathrm{L}$ : Iron deficiency: differential effects on monoamine transporters. Nutr Neurosci 2005, 8(1):31-38.

22. Parks YA, Wharton BA: Iron deficiency and the brain. Acta Paediatr Scand Suppl 1989, 361:71-77.

23. Beard JL, Unger EL, Bianco LE, Paul T, Rundle SE, Jones BC: Early postnatal iron repletion overcomes lasting effects of gestational iron deficiency in rats. J Nutr 2007, 137(5):1176-1182.

24. Erikson KM, Jones BC, Beard JL: Iron deficiency alters dopamine transporter functioning in rat striatum. J Nutr 2000, 130(11):2831-2837.

25. Erikson KM, Jones BC, Hess EJ, Zhang Q, Beard JL: Iron deficiency decreases dopamine D1 and D2 receptors in rat brain. Pharmacol Biochem Behav 2001, 69(3-4):409-418.

26. Pinero DJ, Li NQ, Connor JR, Beard JL: Variations in dietary iron alter brain iron metabolism in developing rats. J Nutr 2000, 130(2):254-263.

27. Anderson JG, Fordahl SC, Cooney PT, Weaver TL, Colyer CL, Erikson KM: Extracellular norepinephrine, norepinephrine receptor and transporter protein and mRNA levels are differentially altered in the developing rat brain due to dietary iron deficiency and manganese exposure. Brain Res 2009, 1281:1-14.

28. Erikson KM, Syversen T, Steinnes E, Aschner M: Globus pallidus: a target brain region for divalent metal accumulation associated with dietary iron deficiency. J Nutr Biochem 2004, 15(6):335-341.

29. Shukla A, Agarwal KN, Chansuria JP, Taneja V: Effect of latent iron deficiency on 5-hydroxytryptamine metabolism in rat brain. J Neurochem 1989, 52(3):730-735.

30. Grantham-McGregor S, Ani C: A review of studies on the effect of iron deficiency on cognitive development in children. J Nutr 2001, 131(2S-2):649S-666S. discussion 666S-668S.

31. Lozoff B, Jimenez $E$, Wolf AW: Long-term developmental outcome of infants with iron deficiency. N Engl J Med 1991, 325(10):687-694.

32. Cortese S, Azoulay R, Castellanos FX, Chalard F, Lecendreux M, Chechin D, Delorme R, Sebag G, Sbarbati A, Mouren MC, et al: Brain iron levels in attention-deficit/hyperactivity disorder: A pilot MRI study. World J Biol Psychiatry 2012, 13(3):223-231.

33. Oner O, Alkar OY, Oner P: Relation of ferritin levels with symptom ratings and cognitive performance in children with attention deficithyperactivity disorder. Pediatr Int 2008, 50(1):40-44.

34. Millichap JG, Yee MM, Davidson SI: Serum ferritin in children with attention-deficit hyperactivity disorder. Pediatr Neurol 2006, 34(3):200-203.

35. Herguner S, Kelesoglu FM, Tanidir C, Copur M: Ferritin and iron levels in children with autistic disorder. Eur J Pediatr 2012, 171(1):143-146. 
36. Latif $A$, Heinz $P$, Cook R: Iron deficiency in autism and Asperger syndrome. Autism 2002, 6(1):103-114.

37. Chen MH, Su TP, Chen YS, Hsu JW, Huang KL, Chang WH, Bai YM: Attention deficit hyperactivity disorder, tic disorder, and allergy: Is there a link? A nationwide population-based study. J Child Psychol Psychiatry 2013, 54(5):545-551.

38. Chen MH, Su TP, Chen YS, Hsu JW, Huang KL, Chang WH, Bai YM: Allergic rhinitis in adolescence increases the risk of depression in later life: a nationwide population-based prospective cohort study. J Affect Disord 2013, 145(1):49-53

39. Li CT, Bai YM, Huang YL, Chen YS, Chen TJ, Cheng JY, Su TP: Association between antidepressant resistance in unipolar depression and subsequent bipolar disorder: cohort study. Br J Psychiatry 2012, 200(1):45-51.

40. Lozoff B, Jimenez E, Hagen J, Mollen E, Wolf AW: Poorer behavioral and developmental outcome more than 10 years after treatment for iron deficiency in infancy. Pediatrics 2000, 105(4):E51.

41. Pollitt E: Early iron deficiency anemia and later mental retardation. Am J Clin Nutr 1999, 69(1):4-5.

42. Beltran-Navarro B, Matute E, Vasquez-Garibay E, Zarabozo D: Effect of chronic iron deficiency on neuropsychological domains in infants. J Child Neurol 2012, 27(3):297-303.

43. Halterman JS, Kaczorowski JM, Aligne CA, Auinger P, Szilagyi PG: Iron deficiency and cognitive achievement among school-aged children and adolescents in the United States. Pediatrics 2001, 107(6):1381-1386.

44. Menegassi M, Mello ED, Guimaraes LR, Matte BC, Driemeier F, Pedroso GL, Rohde LA, Schmitz M: Food intake and serum levels of iron in children and adolescents with attention-deficit/hyperactivity disorder. Rev Bras Psiquiatr 2010, 32(2):132-138.

45. Tan LN, Wei HY, Zhang YD, Lu AL, Li Y: Relationship between serum ferritin levels and susceptibility to attention deficit hyperactivity disorder in children: a Meta analysis. Zhongguo Dang Dai Er Ke Za Zhi 2011, 13(9):722-724.

46. Lozoff B: Iron deficiency and child development. Food Nutr Bull 2007 28(4 Suppl):S560-571.

47. Lozoff B, Corapci F, Burden MJ, Kaciroti N, Angulo-Barroso R, Sazawal S, Black M: Preschool-aged children with iron deficiency anemia show altered affect and behavior. J Nutr 2007, 137(3):683-689.

48. Lozoff B, Georgieff MK: Iron deficiency and brain development. Semin Pediatr Neurol 2006, 13(3):158-165.

49. Carmody DP, Lewis M: Regional white matter development in children with autism spectrum disorders. Dev Psychobiol 2010, 52(8):755-763.

50. Conturo TE, Williams DL, Smith CD, Gultepe E, Akbudak E, Minshew NJ: Neuronal fiber pathway abnormalities in autism: an initial MRI diffusion tensor tracking study of hippocampo-fusiform and amygdalo-fusiform pathways. J Int Neuropsycho/ Soc 2008, 14(6):933-946.

51. Weinstein M, Ben-Sira L, Levy $Y$, Zachor DA, Ben Itzhak E, Artzi M, Tarrasch R, Eksteine PM, Hendler T, Ben Bashat D: Abnormal white matter integrity in young children with autism. Hum Brain Mapp 2011, 32(4):534-543.

52. Bodnar LM, Wisner KL: Nutrition and depression: implications for improving mental health among childbearing-aged women. Biol Psychiatry 2005, 58(9):679-685.

53. Vahdat Shariatpanaahi M, Vahdat Shariatpanaahi Z, Moshtaaghi M, Shahbaazi SH, Abadi A: The relationship between depression and serum ferritin level. Eur J Clin Nutr 2007, 61(4):532-535.

54. Yi S, Nanri A, Poudel-Tandukar K, Nonaka D, Matsushita Y, Hori A, Mizoue T: Association between serum ferritin concentrations and depressive symptoms in Japanese municipal employees. Psychiatry Res 2011, 189(3):368-372.

55. Leibenluft E: Severe mood dysregulation, irritability, and the diagnostic boundaries of bipolar disorder in youths. Am J Psychiatry 2011, 168(2):129-142.

56. Phillips ML: The neural basis of mood dysregulation in bipolar disorder. Cogn Neuropsychiatry 2006, 11(3):233-249.

57. Stein DJ, Horn N, Ramesar R, Savitz J: Bipolar disorder: emotional dysregulation and neuronal vulnerability. CNS Spectr 2009, 14(3):122-126

58. Chang S, Wang L, Wang Y, Brouwer ID, Kok FJ, Lozoff B, Chen C: Irondeficiency anemia in infancy and social emotional development in preschool-aged Chinese children. Pediatrics 2011, 127(4):e927-933.

59. Lozoff B: Early iron deficiency has brain and behavior effects consistent with dopaminergic dysfunction. J Nutr 2011, 141(4):740S-746S.

60. Schmidt AT, Ladwig EK, Wobken JD, Grove WM, Georgieff MK: Delayed alternation performance in rats following recovery from early iron deficiency. Physiol Behav 2010, 101(4):503-508.
61. Shukla A, Agarwal KN, Shukla GS: Latent iron deficiency alters gammaaminobutyric acid and glutamate metabolism in rat brain. Experientia 1989, 45(4):343-345

62. Beard JL, Erikson KM, Jones BC: Neurobehavioral analysis of developmental iron deficiency in rats. Behav Brain Res 2002, 134(1-2):517-524.

63. Suveg C, Morelen D, Brewer GA, Thomassin K: The emotion dysregulation model of anxiety: a preliminary path analytic examination. J Anxiety Disord 2010, 24(8):924-930.

64. Weems CF, Silverman WK: An integrative model of control: implications for understanding emotion regulation and dysregulation in childhood anxiety. J Affect Disord 2006, 91(2-3):113-124.

65. Mennin DS, Heimberg RG, Turk CL, Fresco DM: Preliminary evidence for an emotion dysregulation model of generalized anxiety disorder. Behav Res Ther 2005, 43(10):1281-1310.

66. Giedd JN, Rapoport JL: Structural MRI of pediatric brain development: what have we learned and where are we going? Neuron 2010, 67(5):728-734.

67. Toga AW, Thompson PM, Sowell ER: Mapping brain maturation. Trends Neurosci 2006, 29(3):148-159.

68. Cortese S, Lecendreux M, Bernardina BD, Mouren MC, Sbarbati A, Konofal E: Attention-deficit/hyperactivity disorder, Tourette's syndrome, and restless legs syndrome: the iron hypothesis. Med Hypotheses 2008 70(6):1128-1132

69. Gorman DA, Zhu H, Anderson GM, Davies M, Peterson BS: Ferritin levels and their association with regional brain volumes in Tourette's syndrome. Am J Psychiatry 2006, 163(7):1264-1272.

doi:10.1186/1471-244X-13-161

Cite this article as: Chen et al.: Association between psychiatric disorders and iron deficiency anemia among children and adolescents: a nationwide population-based study. BMC Psychiatry 2013 13:161.

\section{Submit your next manuscript to BioMed Central and take full advantage of:}

- Convenient online submission

- Thorough peer review

- No space constraints or color figure charges

- Immediate publication on acceptance

- Inclusion in PubMed, CAS, Scopus and Google Scholar

- Research which is freely available for redistribution 